\title{
DECOMPRESSION AND HEATING INDUCED AMPHIBOLE BREAKDOWN IN EFFUSIVE VOLCANISM ON DOMINICA, LESSER ANTILLES
}

ABADIE LUDLAM, Union College

Research Advisor: Holli Frey

\section{INTRODUCTION}

Amphibole stability is generally dictated by the water content of a melt, which can be changed by heating or decompression. As these processes occur and water content decreases, amphibole becomes unstable and begins to break down (Fig. 1). This breakdown occurs as an open system reaction with the surrounding melt, creating new minerals in the place of amphibole (Fig. 1; Buckley et al., 2006; Plechov et al., 2008). The result is a reaction rim usually composed of plagioclase, orthopyroxene (opx), clinopyroxene (cpx), and Fe-Ti oxides (Rutherford and Hill, 1993; Rutherford and Devine, 2003; Browne and Gardner, 2006; De Angelis et al., 2013; De Angelis et al., 2015). Many authors (Rutherford and Hill, 1993; Browne and Gardner, 2006; Plechov et al., 2008; De Angelis et al., 2013) have investigated both natural and experimentally created breakdown rim textures, but little consensus has been made about the types of textures that can be created and by what process.

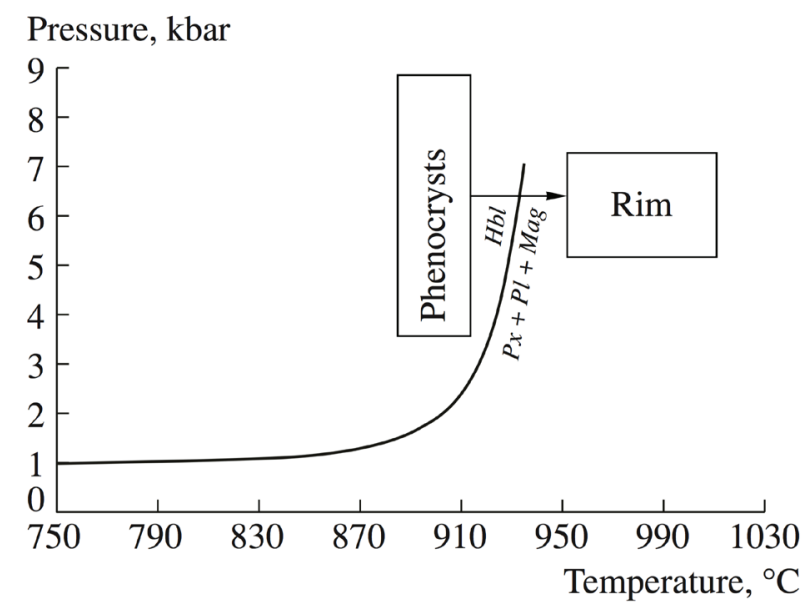

Figure 1. An experimentally derived amphibole stability field for dacite that was used in this as an approximate stability field for the samples in this study. From Plechov et al., 2008.
Decompression induced rims occur as magma rises slowly enough for amphibole to spend adequate time in pressures where it is unstable and can react with the melt. In decompression induced rims, the ascent rate of the magma determines the thickness of the rims (Rutherford and Hill, 1993; Rutherford and Devine, 2003; Plechov et al., 2008). A slower ascent pushes amphibole outside of its stability field for a longer time, allowing breakdown to occur, whereas a fast ascent moves the crystal to the surface quickly, minimizing time for reactions and creating a thin rim or no rim at all (Rutherford and Hill, 1993). Additionally, magma stalling at depth can create zoned rims, with multiple populations of grain sizes (Browne and Gardner, 2006). The relationship between ascent rate and rim thickness has been shown numerous times experimentally, and decompression experiments have allowed calibration curves for rates of ascent to be established for specific melt compositions (Rutherford and Hill, 1993; Plechov et. al, 2008). Ascent rates are generally on the order of days to weeks (Rutherford and Hill, 1993; Plechov et. al, 2008).

Heating induced reaction rims are often attributed to mafic injections and can occur in as little as 3 hours at $10-15^{\circ} \mathrm{C}$ above the amphibole stability field (Rutherford and Devine, 2003; De Angelis et al., 2013; De Angelis et al., 2015). The extent of breakdown depends on the degree of heating. In extreme cases, complete breakdown can occur in just 36 hours, but prolonged heating at a lower temperature causes little change in rim thickness (De Angelis et al., 2015).

This study aims to characterize and understand the cause of amphibole breakdown in lava domes on Dominica, Lesser Antilles. Four andesitic-dacitic lava 
domes (60-64 \% $\left.\mathrm{SiO}_{2}\right)$ from different locations and varying ages were studied: Espagnol (ESP, $744 \pm 44$ ka), La Falaise (LF, $84 \pm 5 \mathrm{ka})$, Canot (CAN, $<50$ ka), and Patates (MPP, $510 \pm 9$ yrs) (Project Director's Fig. 1; Lindsay, 2003; Howe et al., 2015). ESP is on the northwestern coast, and the others are located in the Plat Pays complex in the southwestern region of the island. These domes exhibit drastically different extents of breakdown, and our goal was to understand what was causing breakdown and why it was different between domes.

\section{METHODS}

A Zeiss EVO-MA15 scanning electron microscope (SEM), along with a back scattered electron (BSE) detector were used to image thin sections of the samples. Running with the SEM, a Bruker EDX system was used to create elemental maps and determine compositions of minerals in the samples. Oxide quantitative analysis was performed using a $5 \mu \mathrm{m}$ beam spot, standardizing $\mathrm{Mg}$ and $\mathrm{Al}$ on spinel, $\mathrm{Ti}$ on rutile, $\mathrm{Fe}$ on hematite, and $\mathrm{Si}, \mathrm{Ca}$, and $\mathrm{Mn}$ on spessartine, with ilmenite as a secondary standard. Plagioclase analysis was performed using a $10 \mu \mathrm{m}$ by $10 \mu \mathrm{m}$ rastered box, standardizing $\mathrm{Mg}$ and $\mathrm{Si}$ on augite, $\mathrm{K}$ on microcline, $\mathrm{Na}$ on albite, and $\mathrm{Al}, \mathrm{Ca}$, and $\mathrm{Fe}$ on grossular, with labradorite as a secondary standard. For all analyses, the beam current was $15 \mathrm{kV}$.

Rim thicknesses were measured on crystals in ESP and MPP using ImageJ. Thicknesses were taken at the thinnest and thickest points of each rim, and 2 to 3 other evenly spaced points on the rim.

After compositions were obtained, crystallization temperatures of all possible pairs of Fe-Ti oxides were found using the Ghiorso and Evans (2008) thermometer, aided by the Hora et al. (2013) Excel script. Due to the scarcity of oxides in our samples, all temperatures were considered, regardless of if the oxide pairs passed the Bacon-Hirschmann (1988) Mg/ Mn test of equilibrium. Water contents and depths were found using these temperatures, plagioclase compositions, whole rock geochemistry as a proxy for magmatic liquid, and the plagioclase hygrometer of Waters and Lange (2015).

\section{RESULTS}

\section{Amphibole Breakdown Textures}

Six breakdown textures were observed among the four samples: two thin rimmed textures and four pseudomorph textures. Each sample contained either thin rimmed textures or pseudomorph textures, but not both. All textures were composed of plagioclase, pyroxene, and oxides.

Thin rimmed breakdown textures were observed in two samples: ESP and MPP (Fig. 2). Each sample had a distinct texture that made up $100 \%$ of their observed hornblende crystals. Type 1, found in ESP, is equigranular, fine grained, and ranged from 8 to 82 $\mu \mathrm{m}$. Thicknesses does not correlate to crystal size, and rim thickness is highly variable on individual crystals. The texture often surrounds inclusions and extends into cleavage planes. Type 2, found in MPP, is also equigranular and fine grained, but with thinner rims than type 1, with nearly all rims between 6 and $22 \mu \mathrm{m}$. Thickness again does not correlate to crystal size. The texture is rarely found around inclusions or along cleavage planes, and rim thicknesses are more consistent on each crystal and throughout the sample than type 1 . Oxides are notably scarce in type 2 .

The four pseudomorph textures are shared between LF and CAN (Fig. 3). Types 3, 4, and 5 were found in both samples, and type 6 is unique to CAN. Type 3 consists of an equigranular center and a finer grained rim with noticeabley fewer oxides than the core. Type 4 is characterized by multiple zones of distinguishable differences in grain size and relative mineral abundances. Grains with this texture tend to sharply preserve amphibole shape. Type 5 is a grungy texture, with no distinguishable grain shape. Type 6 is the coarsest grained texture, and the amphibole shape appears to be disaggregating.

\section{Oxide Temperatures}

Temperatures were found for the matrix, reaction texture, and inclusions for LF and CAN, but only for the matrix and inclusions for ESP and MPP because their rims were too fine grained to obtain an accurate analysis (Fig. 4). Temperatures in ESP were 710$870{ }^{\circ} \mathrm{C}$ in the matrix $(\mathrm{n}=42)$ and $820-920^{\circ} \mathrm{C}$ in the 

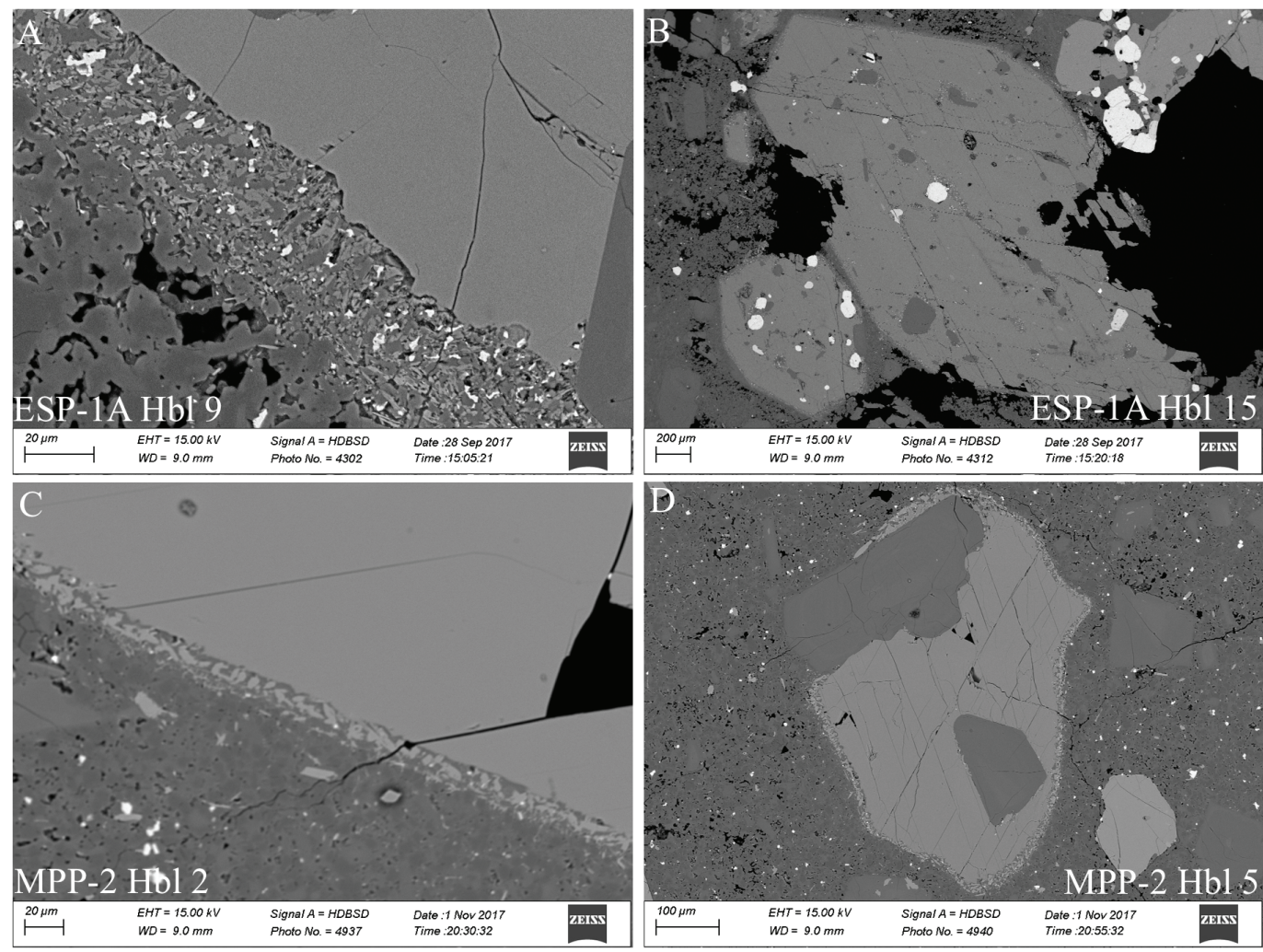

Figure 2. BSE images of thin rimmed reaction textures, both consisting of plagioclase, pyroxene, and oxides. A, B: Type 1, found in ESP only, is the thicker of the two textures. C, D: Type 2, found in MPP-2 only, contains noticeably fewer oxides than type 1.

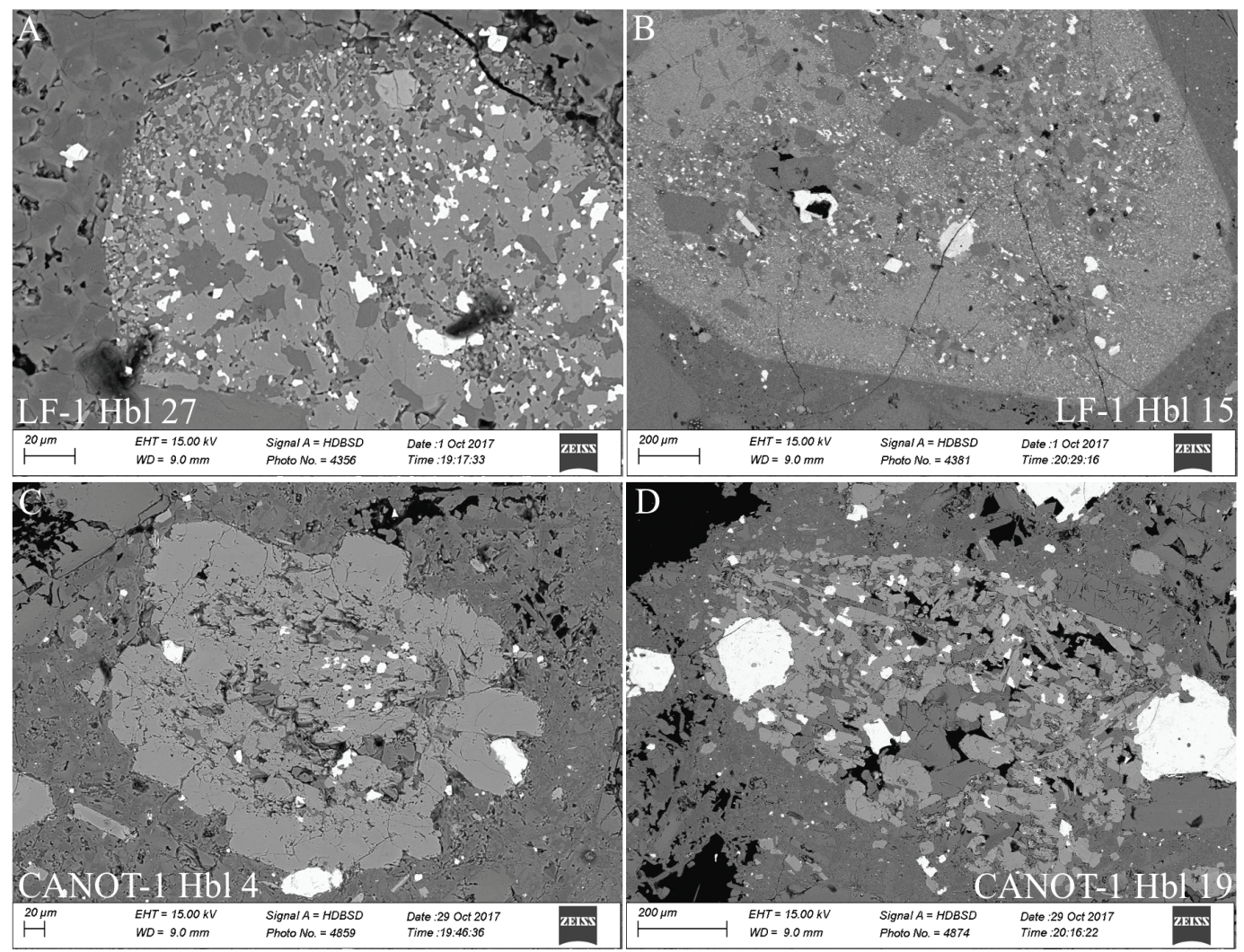

Figure 3. BSE images of hornblende pseudomorphs. A: Type 3, a coarse interior and fine grained, oxide poor exterior. B: Type 4, zoned by grain size. C: Type 5, grungy with indistinguishable shape. D: Type 6, coarse grained and shape disaggregating. 

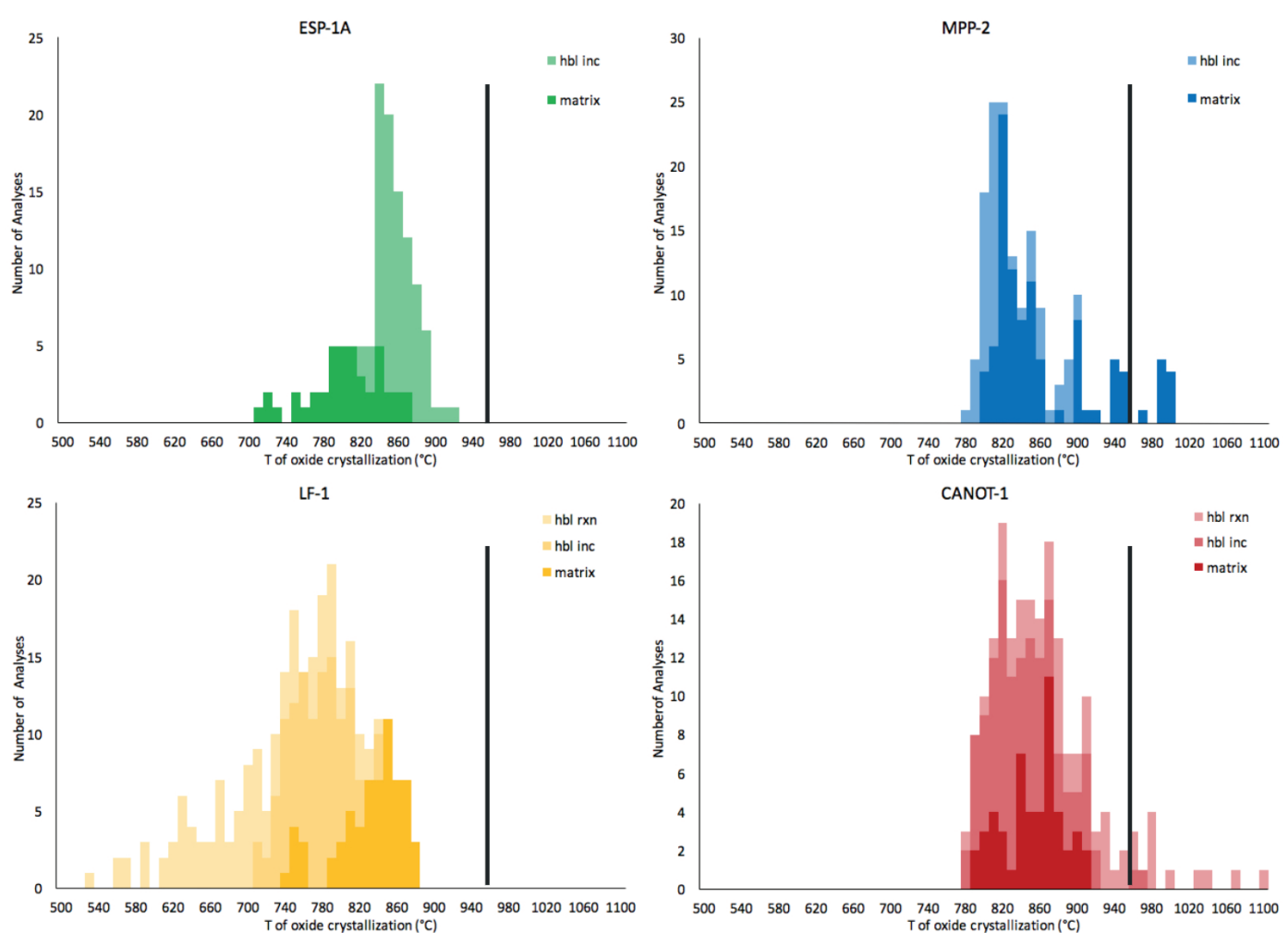

Figure 4. Temperatures of oxide crystallization, found using oxide compositions and Ghiorso and Evans 2008 geothermometer.

inclusions $(\mathrm{n}=81)$. In MPP, temperatures ranged from $800-1000{ }^{\circ} \mathrm{C}$ in the matrix $(\mathrm{n}=100)$ and 780 $900{ }^{\circ} \mathrm{C}$ in inclusions $(\mathrm{n}=60)$. In $\mathrm{LF}$, temperatures ranged from $740-880^{\circ} \mathrm{C}$ in the matrix $(\mathrm{n}=64), 710$ $840{ }^{\circ} \mathrm{C}$ in inclusions $(\mathrm{n}=100)$, and $530-830{ }^{\circ} \mathrm{C}$ in the reaction texture $(n=100)$. Temperatures in CAN were relatively constant. They ranged from $790-910{ }^{\circ} \mathrm{C}$ in the matrix $(\mathrm{n}=50), 780-970{ }^{\circ} \mathrm{C}$ in inclusions $(\mathrm{n}=88)$, and $780-1100{ }^{\circ} \mathrm{C}$ in the reaction texture $(\mathrm{n}=50)$.

\section{Plagioclase Compositions}

Plagioclase rim compositions were found for all four samples, and core compositions were found for ESP and LF. In both ESP and LF, core compositions were more anorthitic and wider ranging than rim compositions. Rim compositions in ESP ranged from $\mathrm{An}_{34}$ to $\mathrm{An}_{62}(\mathrm{n}=36)$ and core compositions ranged from $\mathrm{An}_{48}$ to $\mathrm{An}_{82}(\mathrm{n}=54)$. LF rim compositions ranged from $\mathrm{An}_{42}$ to $\mathrm{An}_{66}(\mathrm{n}=27)$ and core compo-sitions from $\mathrm{An}_{44}$ to $\mathrm{An}_{90}(\mathrm{n}=67)$. In MPP, rim compositions ranged from $\mathrm{An}_{48}$ to $\mathrm{An}_{60}(\mathrm{n}=31)$. Rim compositions of CAN ranged from $\mathrm{An}_{46}$ to $\mathrm{An}_{92}(\mathrm{n}=30)$.
Plagioclase rim compositions, whole rock geochemistry, and oxide temperatures were used to determine the minimum and maximum water content of the latest crystallized melt, yielding 6.8-7.2 $\mathrm{wt} \%$ in ESP, 6.7-6.8 wt $\%$ in MPP, 8.6-8.8 wt $\%$ in LF, and 6.5-6.8 wt $\%$ in CAN. These water contents, oxide temperatures, and whole rock geochemistry were then used to find the pressures when plagioclase rims were crystallizing. These pressures were 3100-3450 bars for ESP, 30503100 bars for MPP, 4800-5000 bars for LF, and 30003250 bars for CAN.

\section{Elemental Mapping}

Elemental maps displaying $\mathrm{Mg}, \mathrm{Ca}$, and Fe reveal the composition of pyroxenes in each samples' reaction textures (Fig. 5). MPP rims contain negligible $\mathrm{Ca}$ and significant $\mathrm{Mg}$ and $\mathrm{Fe}$, indicating that $\mathrm{cpx}$ is absent in the rims, whereas opx is abundant. LF and CAN have many grains with a combination of $\mathrm{Mg}$ and $\mathrm{Ca}$, as well as grains that contain only $\mathrm{Mg}$, indicating an abundance of both cpx and opx. ESP rims shows two distinct zones, with an abrupt boundary between, of pyroxene composition. The inner looks similar to LF 


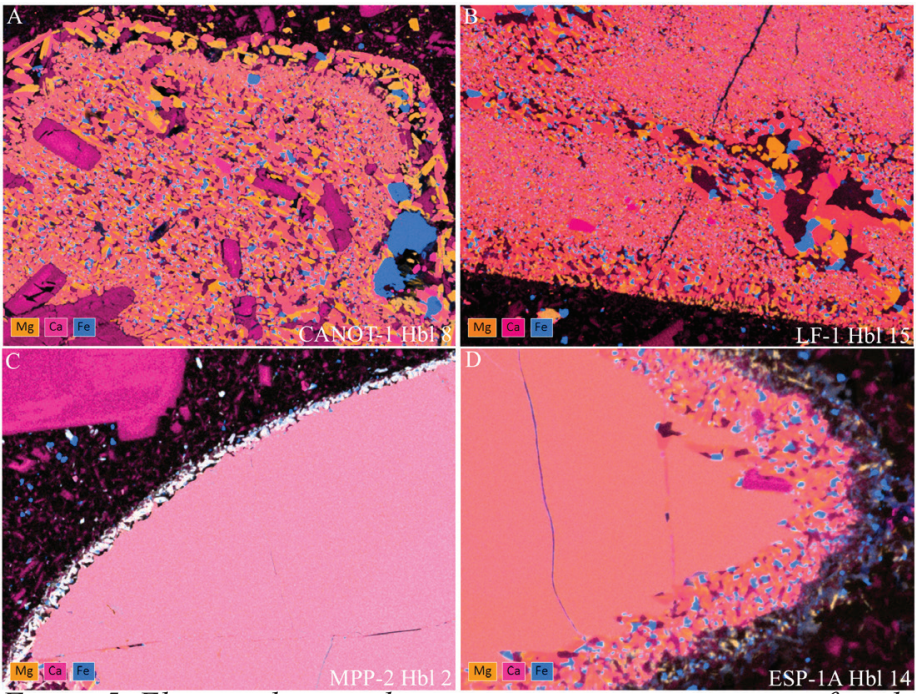

Figure 5. Elemental maps showing pyroxene composition of each sample's breakdown texture.

and CAN and is cpx rich, and the outer looks similar to MPP, lacking cpx.

\section{DISCUSSION}

The abundance, or lack thereof, of cpx in the reaction textures of the amphibole may be diagnostic of the cause of amphibole breakdown. De Angelis et al. (2015) found that in experiments at several temperatures, cpx was lost after 36 to 48 hours of heating, and for certain temperatures, prolonged heating did not cause a substantial growth in rim thickness.

The lack of cpx in MPP's rims and the finding that prolonged heating may not cause complete breakdown suggests heating is the cause of amphibole breakdown in MPP. This is consistent with several of its oxide temperatures exceeding $950{ }^{\circ} \mathrm{C}$, the approximate upper limit of amphibole stability in an experimental dacite (Figs. 1 and 4; Plechov et al., 2008)

In LF and CANOT, the presence of cpx in breakdown textures points to decompression as the cause of amphibole breakdown. Zonation of breakdown textures into zones of varying grain size, like that observed in LF and CANOT, has been attributed to magmatic stalling at different depths (Fig. 3B; Browne and Gardner, 2006). The extent of breakdown in these samples, along with their zoning, indicates that they rose slowly, stalling several times on their ascent to the surface.
The mineralogically distinct reaction zones observed in ESP's elemental maps suggests two separate events causing breakdown. The inner zone, containing cpx, was likely caused by decompression, whereas the outer zone, lacking cpx, was likely caused by heating. Though none of the oxide temperatures found in ESP exceeded $950{ }^{\circ} \mathrm{C}$, temperatures were not found for its rims. Amphibole breakdown is usually thought to occur from the outside in, so it is likely that the outer zone is the older one and heating occurred first (Rutherford and Hill, 1993). It is also possible that the outer zone is caused by a reaction between the melt and the inner zone, suggesting that decompression occurred first.

There are no trends connecting extent or cause of breakdown to the age, place, or geochemistry of each lava dome. ESP (heating and decompression) and LF (decompression) have slightly higher $\mathrm{SiO} 2$ content than CANOT (decompression) and MPP (heating), showing no correlation between whole rock chemistry and cause of breakdown. Though two of the southern domes, LF and CANOT, share pseudomorph textures and decompression induced breakdown, the third southern dome, MPP, contains thin rims created by heating. The northern dome, ESP, appears to have been created by a mix of these processes, so there is no relationship between geographic location and cause of breakdown. There is no consistent trend over time either. The oldest dome, ESP, and the youngest dome, MPP, are the two domes with evidence of heating. These results suggest that melt ascent paths are not consistent over time or space and may instead reflect small batches of melt with unique ascent paths.

\section{CONCLUSIONS}

Amphiboles from ESP and MPP are characterized by thin, fine-grained reaction rims, whereas those from LF and CAN exhibit complete breakdown. Six reaction textures were found in the four samples, all consisting of plagioclase, pyroxene, and oxides. ESP and MPP each possess a distinct thin rimmed texture, and LF and CAN share four pseudomorph textures. Elemental mapping was used to determine the abundance of cpx in each sample, as the presence of cpx would suggest heating induced breakdown. MPP's rims contain no cpx, indicating that breakdown was most likely caused by heating. This is consistent with 
temperatures found using oxide pair compositions, several of which are above amphibole's $950{ }^{\circ} \mathrm{C}$ temperature stability limit in dacite. Pseudomorphs in LF and CAN contain abundant cpx, making decompression the probable cause of breakdown. The complete breakdown of LF and CAN and zoning in their reaction textures imply that they ascended slowly, stalling multiple times. Elemental maps of ESP show two distinct zones, one with and one without cpx, suggesting two phases of breakdown caused by separate heating and decompression events. The lack of correlation between cause of breakdown and the age and location of samples suggests that lava dome ascent paths on the island are changing over time and space.

\section{ACKNOWLEDGMENTS}

This material is based upon work supported by the Keck Geology Consortium and the National Science Foundation under Grant No. 1659322. Thank you to Holli Frey and Matt Manon for their guidance throughout this project.

\section{REFERENCES}

Bacon, C.R., and Hirshmann, M.M., 1988, Mg/Mn partitioning as a test for equilibrium between coexisting Fe-Ti oxides: American Mineralogist, 73, p. 57-61.

Browne, B.L., and Gardner, J.E., 2006, The influence of magma ascent path on the texture, mineralogy, and formation of hornblende reaction rims: Earth and Planetary Science Letters, 246, p. 161-176.

Buckley, V.J.E., Sparks, R.S.J., Wood, B.J., 2006, Hornblende dehydration reactions during magma ascent at Soufriere Hills Volcano, Montserrat: Contributions to Mineralogy and Petrology, 151, p. 121-140.

De Angelis, S.H., Larsen, J., Coombs, M., 2013, Pre-eruptive magmatic conditions at Augustine Volcano, Alaska, 2006: Evidence from amphibole geochemistry and textures: Journal of Petrology, 54, p. 1939-1961.

De Angelis, S.H., Larsen, J., Coombs, M., Dunn, A., Hayden, L., 2015. Amphibole reaction rims as a record of pre-eruptive magmatic heating: An experimental approach: Earth and Planetary Science Letters, 426, p. 235-245.
Ghiorso, M.S. and Evans, B.W., 2008, Thermodynamics of rhombohedral oxide solid solutions and a revision of the Fe-Ti twooxide geothermometer and oxygen barometer: American Journal of Science, 308, p. 957-1039. Hora, J.M., Kronz, A., Moller-McNett, S., Worner, G., 2013, An Excel-based tool for evaluating and visualizing geothermobarometry data: Computers \& Geosciences, 56, p. 178-185.

Howe, T.M., Schmitt, A.K., Lindsay, J.M., Stockli, D.F., 2015, Time scales of intra-oceanic arc magmatism from combined U-Th and (U-Th)/ He zircon geochronology of Dominica, Lesser Antilles: Geochemistry, Geophysics, Geosystems, 16.

Lindsay, J.M., Stasiuk, M.V., Shepherd, J.B., 2003, Geological history and potential hazards of the late-Pleistocene to Recent Plat Plays volcanic complex, Dominica, Lesser Antilles: Bulletin of Volcanology, 65, p. 201-220.

Plechov, P.Y., Tsai, A.E., Shcherbakov, V.D., Dirksen, O.V., 2008, Opacitization conditions of hornblende in Bezymyanni Volcano andesites (March 30,1956 eruption): Petrology, 16, p. 1935 .

Rutherford, M.J. and Devine, J.D., 2003, Magmatic conditions and magma ascent as indicated by the hornblende phase equilibria and reactions in the 1995-2002 Soufriere Hills magma: Journal of Petrology, 44, p. 1433-1454.

Rutherford, M.J. and Hill, P.M., 1993, Magma ascent rates from amphibole breakdown: An experimental study applied to the 19801986 Mount St. Helens Eruptions: Journal of Geophysical Research, 98, p. 19667-19685.

Waters, L. E., Lange, R. A., 2015, An updated calibration of the plagioclase-liquid hygrometerthermometer applicable to basalts through rhyolites, American Mineralogist, 100, p. 21722184. 